\title{
When the Embers Grow Dim: The Emotional Toll of Primary Care Practice
}

\author{
Robin S. Gotler, MA, Reflections Editor \\ Ann Fam Med 2015;13(3):iii. doi: 10.1370/afm.1796.
}

$\mathrm{T}$ The Annals of Family Medicine encourages readers to develop a learning community of those seeking to improve health care and health through enhanced primary care. You can participate by conducting a RADICAL journal club and sharing the results of your discussions in the Annals online discussion for the featured articles. RADICAL is an acronym for Read, Ask, Discuss, Inquire, Collaborate, Act, and Learn. The word radical also indicates the need to engage diverse participants in thinking critically about important issues affecting primary care and then acting on those discussions. ${ }^{1}$

\section{HOW IT WORKS}

In each issue, the Annals selects an article or articles and provides discussion tips and questions. We encourage you to take a RADICAL approach to these materials and to post a summary of your conversation in our online discussion. (Open the article online and click on "TRACK Comments: Submit a comment.") You can find discussion questions and more information online at: http://www.AnnFamMed.org/site/AJC/.

\section{CURRENT SELECTIONS}

\section{Articles for Discussion}

de Schweinitz PA. One cold autumn day. Ann Fam Med. 2015;13(3): 279-281.

Ramia MS. Smiling toothless. Ann Fam Med. 2015;13(3):282-283.

\section{Discussion Tips}

Two essays explore the emotional toll, as well as the deep satisfaction, inherent in primary care practice. In "One Cold Day" a family physician experiences a full gamut of emotions-irritation, empathy, resignation, and cautious optimism - as he deals with a patient whose modifiable behaviors seem unlikely to change. In "Smiling Toothless," a physician in training in a challenging environment rediscovers the meaning of her work.

\section{Discussion Questions}

Both authors work in challenging settings and are emotionally fatigued. Are their emotional experiences relevant to primary care physicians in other settings? Are their stories relevant to your practice?

Ramia tries to protect her emotions by engaging with the condition and not the patient. For de Schweinitz, "sometimes, when my embers have grown dim, the caring looks a bit more like cold, biomedical efficiency." What do you think of these coping mechanisms? How do you cope when your passion for your work runs low?

Surgery, de Schweinitz suggests, is more concrete than family medicine and surgeons are potentially more powerful: "At the end of the day, the surgeon knows she's changed the world. She commands the surgical field. ... What do I command, a steady income?" What sort of power do you have as a primary care clinician? What power do you lack? What is the relationship between your sense of power and your perception of your work as abstract, concrete, or both?

Do you agree with de Schweinitz that, "In primary care, most of our interventions are not determinate. We can only hope to shift the odds in the patient's favor."?

Ramia is able to emotionally re-engage with her work when she sees that she has made a difference in young Mohammad's life. On the other hand, de Schweinitz can only imagine what might become of his patient and whether he made a difference. How important is it to you to know the outcome of your work? What role does continuity with patients play in your sense of professional satisfaction?

In his reflections, de Schweinitz considers the value of listening to patients "if not with welling heart, at least with the integrity of honest intent." Is honest intent enough? Can it substitute for heartfelt compassion?

\section{References}

1. Stange KC, Miller WL, McLellan LA, et al. Annals Journal Club: It's time to get RADICAL. Ann Fam Med. 2006;4(3):196-197. http:// annfammed.org/content/4/3/196. 